\title{
Application of membrane-coupled anaerobic volatile fatty acids fermentor for dissolved organics recovery from coagulated raw sludge
}

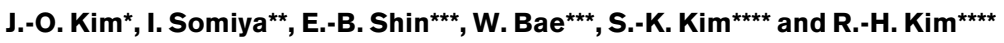 \\ * Department of Civil Engineering, Kangnung National University, Chibyeon-dong 123, Kangnung, \\ Kangwon-do, 210-702, Korea \\ ** Department of Environmental Engineering, Kyoto University, Yoshida honmachi, Sakyo-ku, Kyoto, 606- \\ 8501, Japan \\ *** Department of Civil \& Environmental Engineering, Hanyang University, Ansan, Kyunggi-do, 425-791, \\ Korea

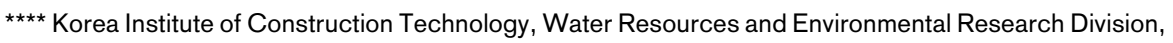 \\ 2311 Daehwa-dong, Ilsan-gu, Goyang, Kyunggi-do, 411-712, Korea
}

\begin{abstract}
To investigate the treatment performance of membrane-coupled anaerobic volatile fatty acids fermentor system, the effects of operational parameters for volatile fatty acids production were evaluated through experiments and a mathematical model. The volatile fatty acids recovery ratio was largely affected by the change of hydraulic retention time, reaching its maximum value at $12 \mathrm{hrs}$. Over the range of hydraulic retention time 8 to $96 \mathrm{hrs}$, the volatile fatty acids recovery ratio decreased with the increase of hydraulic retention time above $12 \mathrm{hrs}$, while the ratio of mineralization and gasification increased. Hydraulic retention time and membrane filtration ratio should be maintained less than 1 day and above 0.9 , respectively, to attain over $40 \%$ of organic materials recovery ratio at 10 days of solids retention time. When the hydrolysis rate constant was $0.01 \mathrm{hr}^{-1}$, the organic loading rate should be maintained at above $1.0\left(\mathrm{kgC} / \mathrm{m}^{3} / \mathrm{day}\right)$ to attain over $45 \%$ of volatile fatty acids recovery ratio. Based on experimental and simulated results, membranecoupled anaerobic volatile fatty acids fermentor system was thought to be effective for dissolved organics recovery from coagulated sewage sludge.
\end{abstract}

Keywords Coagulated raw sludge; dissolved organics; mathematical model; membrane coupled fermentor; volatile fatty acids

\section{Introduction}

In anaerobic treatment processes, the combination of membrane as solid-liquid separation tool is quite attractive to retain the biomass in the reactor. Although quite a few membranecoupled anaerobic digestion processes have been employed in the wastewater treatment field, much of its use has been limited to stabilize the suspended organic materials and to produce methane. Most researches have focused on the methane-generation phase of the process. Consequently, relatively little attention has been paid to the recovery and reuse of fermentation permeates.

The dissolved organic compounds containing volatile fatty acids (VFAs) can be used effectively as hydrogen donor for biological nitrogen and phosphorous removal. The generation of acid-phase fermentation products in anaerobic digestion can be influenced greatly by operational parameters. An important operational variable, which can be easily manipulated, is the hydraulic retention time (HRT). It can act as a selection parameter for the acidogenic phase only if it encourages the growth of acid formers and concurrently suppress the growth of methane producers (Elefsiniotis and Oldham, 1994).

An appropriate mathematical model is necessary to find out reliable design conditions of a membrane-coupled anaerobic organic acid fermentor (MCAVF) system and to assess its 
performance. Knowledge on the rate-limiting biochemical reaction is important when trying to monitor or to predict the performance of the system. Although many dynamic or steady state models were developed to describe the behavior of anaerobic processes, few models dealt with the kinetics of the MCAVF process. It was not yet sufficiently developed to allow a satisfactory evaluation of the effluent VFAs concentration and to express the influence of other operational parameters.

The purpose of this study was to investigate the performance of a MCAVF system for an effective recovery of dissolved organic materials. The effects of operational parameters such as hydraulic retention time (HRT), refractory material ratio $\left(\mathrm{C}_{\mathrm{r} 0} / \mathrm{C}_{\mathrm{T} 0}\right)$ and hydrolysis rate constant $\left(k_{l}\right)$ were evaluated. A mathematical model was also developed to predict and design adequate operational conditions of the system.

\section{Materials and methods}

\section{System description}

The schematic diagram of a membrane-coupled anaerobic VFAs fermentor system is shown in Figure 1. The system has a total working volume of $76 \mathrm{~L}$ and consists of an anaerobic fermentor coupled with a ceramic micro filtration (MF) module. Coagulated raw sewage sludge with the dosage of polyaluminium chloride (PAC) $(10 \mathrm{mg} / \mathrm{L})$ and ferric chloride $(10 \mathrm{mg} / \mathrm{L})$ was used as the fermentation substrate. Coagulated sludge was prepared through the process of coagulation and flocculation in separate coagulation treatment unit.

In operation, five runs were employed. Experimental conditions are summarized in Table 1. The HRT was set at 8 to $96 \mathrm{hrs,} \mathrm{while} \mathrm{the} \mathrm{solids} \mathrm{retention} \mathrm{time} \mathrm{(SRT)} \mathrm{was} \mathrm{kept} \mathrm{con-}$ stant at $240 \mathrm{hrs}$ by controlling the membrane filtration ratio. The membrane filtration ratio was defined as the volume of membrane permeate per day/volume of input coagulated raw sludge per day. The temperature and OLR of the fermentor were kept a mesophilic condition of $35^{\circ} \mathrm{C} \pm 1$ and 0.6 to $7.5\left(\mathrm{kgC} / \mathrm{m}^{3} /\right.$ day), respectively. Membrane used this study has $1 \mu \mathrm{m}$ of pore size and a ceramic monolith type.

The feed velocity was set to $0.4(\mathrm{~m} / \mathrm{s})$ and the suction pressure was controlled to 38 $(\mathrm{kPa})$. The total solids (TS) concentration of the coagulated raw sludge influent was not adjusted in this experiment to give the conditions of actual treatment. Besides, the quality of the input sludge had a typical daily pattern. To prevent the growth of methanogenic bacteria, the oxidation-reduction potential (ORP) in the fermentor was always kept around

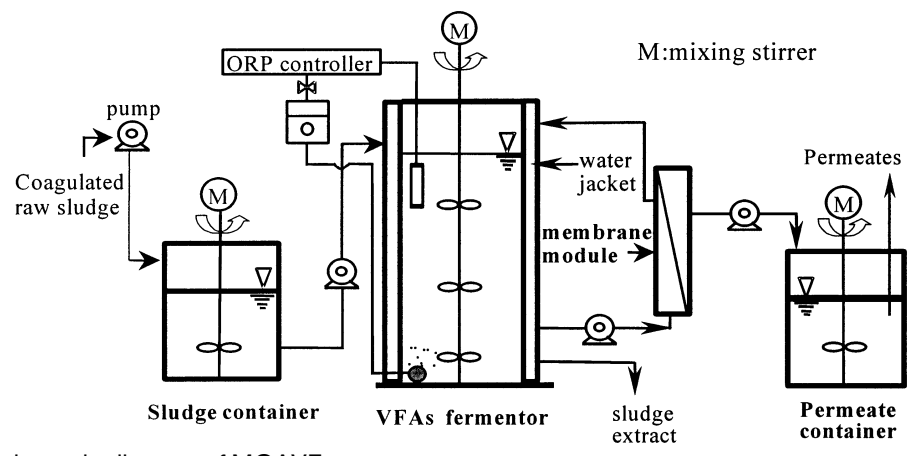

Figure 1 Schematic diagram of MCAVF system

Table 1 Experimental conditions of MCAVF system

\begin{tabular}{lccccc}
\hline & Run 1 & Run 2 & Run 3 & Run 4 & Run 5 \\
\hline HRT (hrs) of anaerobic fermentor & 8 & 12 & 24 & 48 & 96 \\
Filtration ratio (-) of membrane & 0.97 & 0.95 & 0.9 & 0.8 & 0.6 \\
\hline
\end{tabular}


Table 2 The characteristics of influent coagulated sludge

\begin{tabular}{lccc}
\hline Parameter & Range & Mean & Standard Deviation \\
\hline $\mathrm{pH}$ & $6.2-7.1$ & 6.5 & 0.3 \\
$\mathrm{TS}(\mathrm{mg} / \mathrm{L})$ & $4,520-12,350$ & 5,600 & 312 \\
$\mathrm{VS}(\mathrm{mg} / \mathrm{L})$ & $3,616-10,490$ & 4,360 & 278 \\
VSS $(\mathrm{mg} / \mathrm{L})$ & $3,220-9,750$ & 3.960 & 235 \\
$\mathrm{TOC}(\mathrm{mgC} / \mathrm{L})$ & $1,130-3,110$ & 1,820 & 254 \\
VFAs $(\mathrm{mgC} / \mathrm{L})$ & $2-12$ & 5 & 0.5 \\
$\mathrm{NH}_{4}^{+}-\mathrm{N}(\mathrm{mgN} / \mathrm{L})$ & $14-47$ & 19 & 4 \\
Percent of VS Carbohydrate & $31.2-38.7$ & 34 & 0.5 \\
Protein & $25.1-28.2$ & 26 & 1.2 \\
Lipids & $7.6-11.7$ & 9 & 0.9 \\
Fiber & $20.3-30.7$ & 25 & 1.5 \\
\hline
\end{tabular}

$-300 \mathrm{mV}$. The characteristics of the influent coagulated raw sludge are given in Table 2. The organic composition revealed that carbohydrate and protein were the most predominant components in the coagulated raw sludge. Fiber also occupied a large part of the organics. The particulate fraction of the organic matter is very high; the VSS/VS ratio was over $90 \%$.

In analysis, total organic carbon (TOC) was measured with a TOC analyzer (TOC-5000, Shimadzu, Kyoto), and VFAs were measured by a gas chromatograph equipped with a flame ionization detector (GC-14A, Shimadzu, Kyoto). $\mathrm{NH}_{4}{ }^{+}-\mathrm{N}$, protein and carbohydrate concentrations were measured by the indophenols method, Lowry-Folin method and phenol sulfuric acid method with Shimadzu UV-1200, respectively. Total lipids were measured by the dry and wet extraction methods (Triebold and Aurand, 1969). Measurements of other items were conducted in accordance with Standard Methods (APHA, 1997).

\section{Mathematical modeling approach Model description}

In continuous culture of MCAVF process, the substrate was added at an input organic concentration $\left(C_{T 0}\right)$ and a flow rate $(Q)$ to the fermentor while its volume $(V)$ was maintained constant by extracting the same flow rate $\left(Q_{1}+Q_{2}\right)$ of solution $\left(Q_{1}\right.$ : permeate flow rate, $Q_{2}$ : retentate flow rate). The transformation of organic materials and the flow of discharge in the reactor are shown in Figure 2 (a) and Figure 2 (b), respectively.

Transformation paths of input organic materials in MCAVF system were supposed as follows: at first, biodegradable particulate organic matter $\left(C_{1}\right)$ is hydrolyzed by VFAs producing bacteria. Then, the hydrolyzed dissolved organic materials $\left(C_{2}\right)$ were finally converted VFAs $\left(C_{3}\right)$ by acid producing bacteria. Degradable solids or polymer organic materials $\left(C_{1}\right)$ became dissolved organic materials $\left(C_{2}\right)$, acid producing bacteria $(M)$,
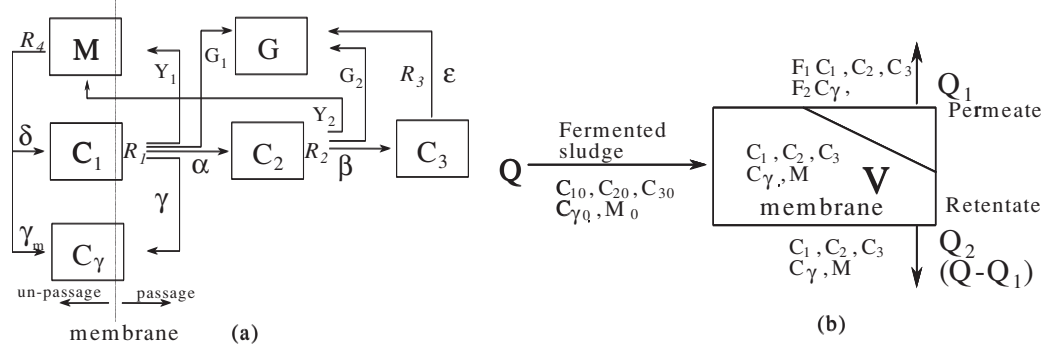

(b)

Figure 2 State variables and transformation paths (a) and the flow of discharge and organic materials (b) in MCAVF system 
recalcitrant organic materials $\left(C_{g}\right)$ and $\mathrm{CO}_{2}\left(G_{1}\right)$ in the ratio of a, $Y_{1}$, g and $G_{1}$, respectively. The sum of a, $Y_{1}, \mathrm{~g}, G_{1}$ equals 1 . Also, dissolved organic materials $\left(C_{2}\right)$ were converted volatile fatty acid $\left(C_{3}\right)$, acid producing bacteria $(M)$ and $\mathrm{CO}_{2}\left(G_{2}\right)$ in the ratio of $\mathrm{b}, \mathrm{Y}_{2}$ and $G_{2}$. b $+Y_{2}+G_{2}$ equals 1 . This mathematical model also considered VFAs consumption caused by intermittent aeration for OPR control in the fermentor. On the other hand, the hydrolysis/acid producing bacteria were self-decomposed, then were converted to degradable solids or polymer organic materials $\left(C_{1}\right)$ and recalcitrant organic materials $\left(C_{\mathrm{r}}\right)$ in the ratio of $\mathrm{d}, \mathrm{g}_{\mathrm{m}}$, respectively. $C_{1}$ and $C_{\mathrm{r}}$ were supposed to pass the membrane at the ratio of $F_{l}$ and $F_{2}$, respectively.

To simplify the development of a mathematical model, the following assumptions were made: 1) The fermentor was completely mixed. 2) $\mathrm{CO}_{2}$ and $\mathrm{H}_{2}$ were only gaseous end products in anaerobic VFAs fermentation. 3) The effect by separation of microbial concentration did not consider in the transformation and consumption of organic materials. 4) Microorganisms were not leaked through the membrane.

Based on the above assumptions, the mass balance in each step was established to find kinetic rate coefficients and unknown variable values with differential equation. The mass balance equation for each state variable, can be written as follows:

$$
\begin{aligned}
& C_{1}: V \frac{d C_{1}}{d t}=Q C_{10}-\left(Q-Q_{1}\right) C_{1}-F_{1} Q_{1} C_{1}-k_{1} C_{1} V+\delta k_{d} M V \\
& C_{2}: V \frac{d C_{2}}{d t}=Q C_{20}-Q C_{2}-k_{2} C_{2} V+\alpha k_{?} C_{1} V \\
& C_{3}: V \frac{d C_{3}}{d t}=Q C_{30}-Q C_{3}+\beta k_{2} C_{2} V-\varepsilon k_{3} C_{3} V \\
& C_{r}: V \frac{d C_{r}}{d t}=Q C_{r 0}-\left(Q-Q_{1}\right) C_{r}-F_{2} Q_{1} C_{r}+\gamma k_{1} C_{1} V+\gamma_{m} k_{d} M V \\
& M: V \frac{d M}{d t}=Q M_{0}-\left(Q-Q_{1}\right) M+Y_{1} k_{1} C_{1} V+Y_{2} k_{2} C_{2} V-k_{d} M V \\
& G: V \frac{d G}{d t}=V\left(1-\alpha-Y_{1}-\gamma\right) k_{1} C_{1}+V\left(1-\beta-Y_{2}\right) k_{2} C_{2}+\varepsilon k_{3} C_{3} V
\end{aligned}
$$

\section{Simulation conditions}

Rate constants, coefficients and selected values used for simulation are listed in Table 3. Data reported in the literature were used as a guidance in selecting values of yield coefficients, self degradation rate coefficient for acid-producing bacteria, transformation ratio of each state variable and membrane passage ratio of both biodegradable particulate organic matter $\left(\mathrm{C}_{1}\right)$ and dissolved organic materials $\left(\mathrm{C}_{2}\right)$. Based on experimental results, the rate coefficient $k_{1}, k_{2}, k_{3}$ and $k_{\mathrm{d}}$ were determined from the above equations.

\section{Results and discussion}

\section{Volatile fatty acids production}

Volatile fatty acids $\left(\mathrm{C}_{2}\right.$ to $\mathrm{C}_{5}$ straight chain and branched) were the main soluble compounds generated during the acidogenic fermentation of coagulated sludge. It was found that VFAs concentrations of fermentor and membrane permeate were essentially identical in all runs (less than $7 \%$ difference).

Table 4 shows the VFAs concentration and distribution as function of HRT. The production rate was largely affected by the change of HRT. The VFAs concentration of permeates was revealed at a maximum value at an HRT of $12 \mathrm{hrs}$. This result indicates that favorable 
Table 3 Rates constants, coefficients and selected values for parameters

\begin{tabular}{lccccc}
\hline Parameter & Unit & Selected value & Parameter & Unit & Selected value \\
\hline$K_{1}$ & $1 / \mathrm{hr}$ & 0.0122 & $Y_{1}$ & - & $0.01^{*}$ \\
$K_{2}$ & $1 / \mathrm{hr}$ & 0.1916 & $Y_{2}$ & - & $0.022^{*}$ \\
$K_{3}$ & $1 / \mathrm{hr}$ & 0.0174 & $F_{1}$ & - & $0.04^{*}$ \\
$K_{\mathrm{d}}$ & $1 / \mathrm{hr}$ & 0.0015 & $F_{2}$ & - & $0.02^{*}$ \\
$\alpha$ & - & 0.85 & $C_{10}$ & $\mathrm{mgC} / \mathrm{L}$ & 1785 \\
$\beta$ & - & 0.75 & $C_{20}$ & $\mathrm{mgC} / \mathrm{L}$ & 50 \\
$\gamma$ & - & 0.01 & $C_{30}$ & $\mathrm{mgC} / \mathrm{L}$ & 5 \\
$\gamma_{m}$ & - & 0.7 & $C_{r O}$ & $\mathrm{mgC} / \mathrm{L}$ & 460 \\
$\delta$ & - & 0.3 & $C_{T O}$ & $\mathrm{mgC} / \mathrm{L}$ & 2300 \\
$\varepsilon$ & - & 0.03 & & & \\
\hline
\end{tabular}

* Reference: (Kim et al., 1995; Yoshikawa, 1994)

conditions for the growth and maintenance of a healthy population of acid-producing bacteria were established in the experimental conditions. The low production rate at a long HRT (96 hrs) might be due to the conversion of soluble VFAs to gaseous products. Therefore, in terms of VFAs production, a long HRT in the fermentor was not favorable.

Identification of the individual acids formed during the acid-phase fermentation of coagulated raw sludge is important, since it can provide valuable information on the stability and dynamics of the system. The most abundant component of volatile fatty acid was acetic acid and the other components were produced in the following order: propionic acid, butyric acid and valeric acid. Despite some variations in the concentrations of the minor acids, the VFAs production was not significantly affected by HRT within the range tested.

\section{Model verification}

Simulation was carried out for steady state and non-steady state values in MCAVF process. The measured and the simulated effluent VFAs concentrations at each HRT are shown in Figure 3. The effluent VFAs concentration data illustrate that there is reasonably good agreement between the measured data and the simulated values. The mathematical model well described the performance of MCAVF process under the conditions investigated.

\section{Effect of operational parameters for VFAs production}

Hydrolysis rate constant $\left(k_{1}\right)$ and organic loading rate $(O L R)$. Because solids and polymer organic materials in the influent contained miscellaneous materials, hydrolysis rate constant was changed by their components. Figure 4 shows the results of the model prediction associated with the variation of hydrolysis rate constant $\left(k_{1}\right)$ and organic loading rate (OLR) at the same time. Here, if the filtration ratio was set to $f$, the VFAs recovery ratio can be expressed as $\left(\mathrm{C}_{3} * f\right) / \mathrm{C}_{\mathrm{T} 0}$. As an evaluation indicator for simulation, VFAs recovery ratio

Table 4 VFAs concentration and distribution as function of HRT

\begin{tabular}{|c|c|c|c|c|c|}
\hline $\begin{array}{l}\text { VFAs } \\
(\mathrm{mg} / \mathrm{L})\end{array}$ & $\begin{array}{c}\text { Run } 1 \\
\text { (HRT } 8 \text { hr) }\end{array}$ & $\begin{array}{c}\text { Run } 2 \\
\text { (HRT } 12 \text { hr) }\end{array}$ & $\begin{array}{c}\text { Run } 3 \\
\text { (HRT } 24 \text { hr) }\end{array}$ & $\begin{array}{c}\text { Run } 4 \\
\text { (HRT } 48 \text { hr) }\end{array}$ & $\begin{array}{c}\text { Run } 5 \\
\text { (HRT } 96 \text { hr) }\end{array}$ \\
\hline Acetic & 336 & 563 & 406 & 411 & 321 \\
\hline Propionic & 264 & 430 & 317 & 253 & 280 \\
\hline N-Butyric & 88 & 72 & 99 & 79 & 107 \\
\hline I-Butyric & 64 & 60 & 60 & 52 & 49 \\
\hline N-Valeric & 24 & 48 & 69 & 44 & 50 \\
\hline I-Valeric & 25 & 24 & 40 & 35 & 16 \\
\hline Total & 801 & 1197 & 991 & 874 & 823 \\
\hline (Permeate TOC/Influent TOC)*100(\%) & 47.2 & 57.6 & 50.1 & 39.4 & 33.1 \\
\hline
\end{tabular}

*Each VFAs concentration was calculated by carbon base 


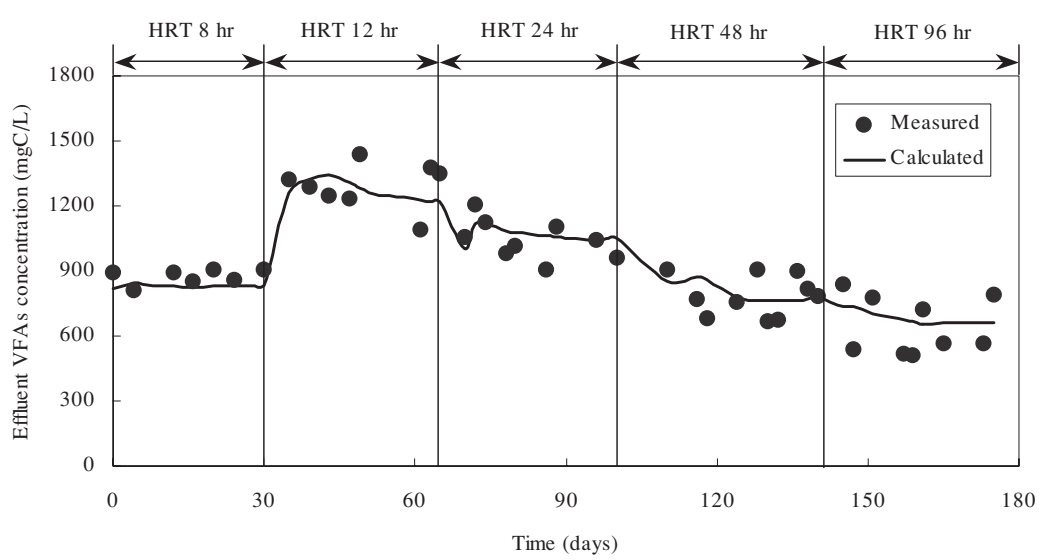

Figure 3 Measured and simulated effluent VFAs concentration data in MCAVF system

was used. In the case hydrolysis rate constants were changed over the range of 0.001 to 0.1 $(1 / \mathrm{hr})$, the value of VFAs recovery ratio was calculated. From Figure 4 , we can see that when OLR declines below certain range, VFAs recovery ratio decreases rapidly. The greater the hydrolysis rate constant was, the greater the effect of VFAs recovery ratio in the OLR range of 0.1 to $1\left(\mathrm{kgC} / \mathrm{m}^{3} \cdot \mathrm{d}\right)$. Accordingly, in case the value of hydrolysis rate constant was $0.01(1 / \mathrm{hr})$, OLR should be maintain above $1.0\left(\mathrm{kgC} / \mathrm{m}^{3} \cdot \mathrm{d}\right)$ to attain over $40 \%$ of VFAs recovery ratio in this system.

Effect of hydraulic retention time (HRT). Relationship between HRT and VFAs recovery and the ratio of mineralization (gasification) are shown in Figure 5 and Figure 6, respectively. The TOC concentration of influent coagulated raw sludge was 2,300 $(\mathrm{mgC} / \mathrm{L})$, and the refractory ratio of influent was assumed to be $20 \%$. As the HRT became longer beyond $12 \mathrm{hr}$, the VFAs recovery ratio decreased, while the ratio of mineralization and gasification increased. The VFAs recovery ratio largely affected by the change of HRT, reaching its maximum value at $12 \mathrm{hr}$. The decline of the ratio with the increase of HRT above the optimum value was partly caused by the conversion of soluble VFAs to mineral or gaseous products. Based on these results, we could infer that the HRT and the filtration ratio respectively should be maintained at less than 1 day and more than 0.9 to attain over $45 \%$ of the VFAs recovery ratio when the SRT was fixed at 10 days.

Effect of refractory material ratio in influent $\left(C_{r o}\right)$. Figure 7 shows the model prediction of the effect of refractory material ratio in the influent on the VFAs recovery ratio. It was

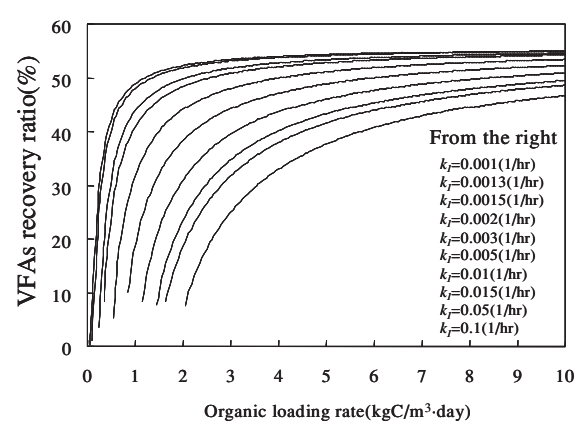

Figure 4 Effect of hydrolysis rate constant and OLR on VFAs recovery ratio

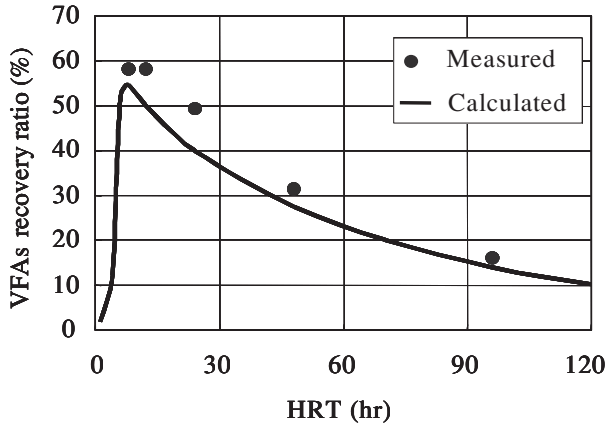

Figure 5 Relationship between VFAs recovery ratio and HRT 


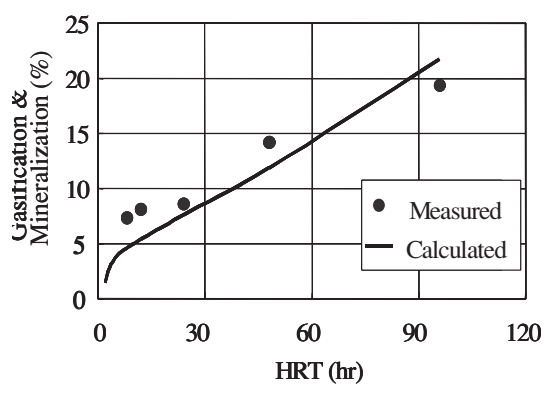

Figure 6 Relationship between mineralization ratio and VFAs recovery ratio

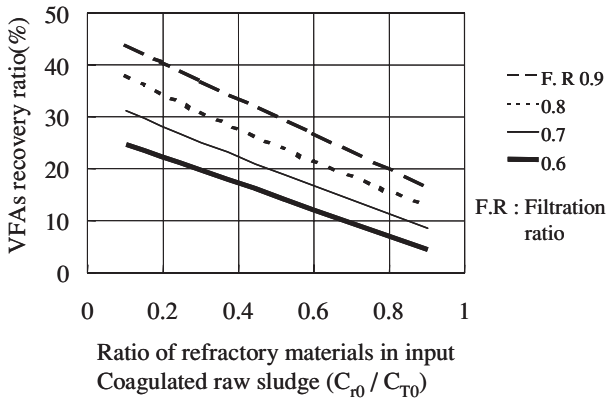

Figure 7 Relationship between refractory materials and HRT

assumed that acid-producing bacteria and dissolved organic materials (hydrolysis unnecessary) were not contained in the input coagulated raw sludge. Figure 7 indicates that the refractory material ratio in the influent is an important factor for VFAs recovery. Since the VFAs recovery decreases substantially with the increase of the refractory material ratio. When the refractory ratio was $10 \%$ of the influent, and the filtration ratio was maintained at 0.9 , the VFAs recovery ratio amounted to $44 \%$.

\section{Material balance}

Material balance on organic matter is shown in Figure 8 with the data when HRT is $12 \mathrm{hrs}$. Samples for analysis were collect at steady state of MCAVF system. Initially, $80 \%$ of the organic matter in the influent (raw sewage) was recovered by coagulation in the primary sedimentation tank. Then, $60 \%$ of the coagulated sludge was used as fermentation substrate. Ultimately, $28 \%$ of the organic matter in influent was recovered as membrane permeates.

\section{Conclusions}

A novel and effective treatment process for dissolved organics recovery was developed. The treatment performance was evaluated by experiments and a mathematical model. The following conclusions were drawn from this study:

1. The hydraulic retention time had a distinct effect at a constant solids retention time on acidogenesis in membrane-coupled anaerobic VFAs fermentor system. Over the range of HRT 8 to 96 (hrs), the VFAs recovery ratio showed its maximum value at $12 \mathrm{hrs,}$ while the ratio of mineralization and gasification was increased with the increase of HRT.

2. To attain over $40 \%$ of organic materials recovery ratio, the HRT and the membrane filtration ratio should be maintained less than 1 day and above 0.9 , respectively, at 10 days of solids retention time.

Unit (gC/day)

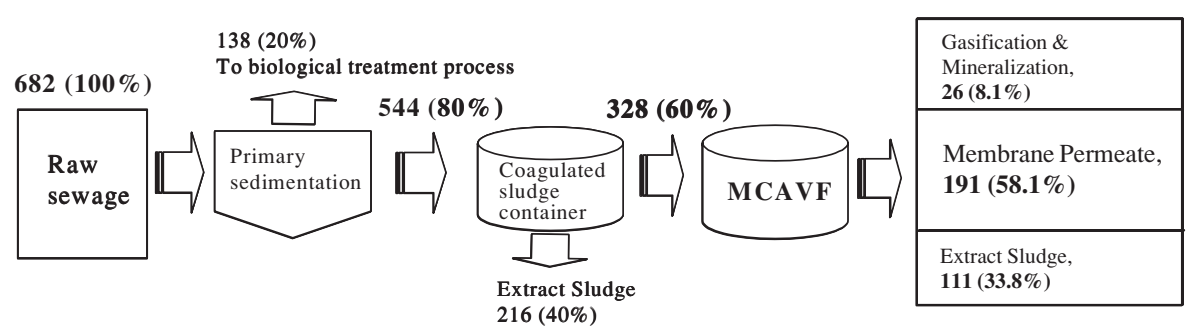

Figure 8 Material balance of organic matter in MCAVF system with pretreatment (HRT = $12 \mathrm{hrs}$ ) 
3. When the hydrolysis rate constant $(k)$ was $0.01(1 / \mathrm{hr})$, the organic loading rate should be maintained above $1.0\left(\mathrm{kgC} / \mathrm{m}^{3}\right.$.day) to attain over $45 \%$ of VFAs recovery ratio.

4. A mathematical model developed in this study described the performance of VFAs production from coagulated sludge.

5. Based on the above results, a MCAVF system was thought to be effective and applicable for dissolved organics recovery.

\section{Nomenclature}

$C_{1}$ : Biodegradable particulate organic matter

$(\mathrm{mgC} / \mathrm{L})$

$\mathrm{C}_{2}$ : Dissolved organic materials (hydrolysis unnecessary)

$(\mathrm{mgC} / \mathrm{L})$

$C_{3}$ : Volatile fatty acids

$(\mathrm{mgC} / \mathrm{L})$

$C_{\gamma}$ : Recalcitrant organic materials

$(\mathrm{mgC} / \mathrm{L})$

$M$ : Hydrolysis and acid producing bacteria

$(\mathrm{mgC} / \mathrm{L})$

$V$ : Fermentor volume

(L)

$Q$ : Input discharge

(L/hr)

$Q_{1}$ : Permeate flow rate

(L/hr)

$k_{1}$ : Hydrolysis rate coefficient

$(1 / \mathrm{hr})$

$k_{2}$ : Acid producing rate coefficient

$(1 / \mathrm{hr})$

$k_{3}$ : VFAs consumption rate coefficient

$(1 / \mathrm{hr})$

$k_{\mathrm{d}}$ : Self degradation rate coefficient for acid production bacteria $\quad(1 / \mathrm{hr})$

$R_{1}$ : Hydrolysis rate

$(\mathrm{mgC} / \mathrm{L} / \mathrm{hr})$

$R_{2}$ : VFAs production rate

$(\mathrm{mgC} / \mathrm{L} / \mathrm{hr})$

$R_{3}$ : Mineralization rate of VFAs

$(\mathrm{mgC} / \mathrm{L} / \mathrm{hr})$

$R_{4}$ : Conversion rate of microorganisms

(mgC/L/hr)

$\alpha$ : Transformation ratio from $C_{1}$ to $C_{2}$

$\beta$ : Transformation ratio from $C_{2}$ to $C_{3}$

$\gamma$ : Transformation ratio from $C_{1}$ to $C_{\mathrm{r}}$

$\gamma_{\mathrm{m}}$ : Transformation ratio from $\mathrm{M}$ to $C_{\mathrm{r}}$

$\delta$ : Transformation ratio from $\mathrm{M}$ to $C_{1}$

$\varepsilon$ : VFAs consumption ratio by aeration

$Y_{1}$ : Yield coefficient from $C_{1}$

$Y_{2}$ : Yield coefficient from $C_{2}$

$G_{1}$ : Mineralization ratio from $C_{1}$

$G_{2}$ : Mineralization ratio from $C_{2}$

$F_{1}$ : Membrane passage ratio of $C_{1}$

$F_{2}$ : Membrane passage ratio of $C_{\mathrm{r}}$

\section{References}

Elefsiniotis, P. and Oldham, W.K. (1994). Effect of HRT on acidogenic digestion of primary sludge. Journal of Environmental Engineering, 120, 645-660.

Ghosh, S., Conrad, J.R. and Klass, D.L. (1975). Anaerobic acidogenesis of wastewater sludge, Journal of Water Pollution Control Federation, (1), pp.31-45.

Kim, D.-H. and Somiya, I. (1995). Study on the organic acid fermentation with membrane filtration, Japan Sewage Works Association research journal (in Japanese), 32(393), pp. 52-63.

APHA (1997). Standard Methods for the Examination of Water and Wastewater (1997). 20th edn, American Public Health Association/American Water Works Association/Water Environment Federation, Washington DC, USA.

Triebold, H.O. and Aurand, L.W. (1969). Food Composition and Analysis, Van Nostrand Reinhold Co., New York, N.Y.

Yoshikawa, S. (1994). Study on the VFAs recovery using membrane filtration, Master thesis, Department of Environmental Engineering, Kyoto University. 
Reproduced with permission of copyright owner. Further reproduction prohibited without permission. 